\title{
A MUDANÇA DO HABITUS DAS INSTITUIÇÕES FEDERAIS DE ENSINO SUPERIOR ATRAVÉS DE POLÍTICAS PÚBLICAS INCLUSIVAS: A NECESSIDADE DE IR MAIS ALÉM
}

\author{
THE HABITUS CHANGE OF FEDERAL HIGHER EDUCATION INSTITUTIONS THROUGH \\ PUBLIC POLICIES OF INCLUSION: THE NEED TO GO FURTHER
}

\section{Pedro Henrique Moreira Cruvinel}

Advogado, regularmente inscrito na OAB/GO sob o no 37.668. Mestre pelo Programa de Pós-Graduação em Direito e Políticas Públicas da UFG. Graduado em Direito pela UFG.

E-mail: pedro20@ufg.br

\section{José Querino Tavares Neto}

Professor Associado da Faculdade de Direito da Universidade Federal de Goiás e Pontifícia Universidade Católica de Goiás. Professor do Programa de Mestrado em Políticas Públicas da UFG. Pós-doutor em Direito Constitucional pela Universidade de Coimbra com bolsa da Capes. Coordenador do Curso de Direito da FANAP. Bolsista de Produtividade do Programa de Pós-Graduação em Direito e Políticas Públicas da UFG e

Bolsista de produtividade do CNPq. E-mail: josequerinotavares@gmail.com

Recebido em: 31/05/2020 Aprovado em: 18/01/2021

\begin{abstract}
RESUMO: O artigo analisa como a formação da sociedade brasileira influenciou a constituição de uma das sociedades mais desiguais do mundo. As instituições de ensino superior, sobretudo as públicas, foram instituídas sob o signo dessa desigualdade, funcionando como instituições legitimadoras. A adoção de políticas públicas inclusivas, por sua vez, conseguiu inserir o jovem das classes menos favorecidas no ambiente universitário. Entretanto, esse é apenas o primeiro passo. É necessário ir além, ou seja, criar políticas públicas para que o egresso das universidades por meio de políticas públicas tenha a mesma oportunidade que os demais. O objetivo do presente artigo, portanto, é analisar como o estamento moldou a sociedade e universidade brasileira, para depois revelar a mudança do habitus no ensino superior e, por fim, apontar alternativas para o fenômeno inflacionário do diploma universitário.
\end{abstract}

Palavras-chave: Instituições de Ensino Superior; estamento social; democratização; habitus; inflação diploma universitário.

\begin{abstract}
The article analyzes how the formation of brazilian society influenced the constitution of one of the most unequal societies in the world. The higher education institutions, especially public ones, were instituted under the sign of this inequality, functioning as legitimizing institutions. The adoption of inclusive public policies, in its turn, managed to insert young people from the least favored classes into the university environment. However, this is only the first step.
\end{abstract}


It is necessary to go further, that is, to create public policies so that university graduates through public policies have the same opportunity as the others. The objective of the present article, therefore, is to analyze how the stratum shaped brazilian society and university, then to reveal the habitus change in higher education and, finally, to point out alternatives for the inflationary phenomenon of the university diploma.

Keywords: Higher Education Institutions; social status; democratization; habitus; university degree inflation.

SUMÁRIO: Introdução; $1 \mathrm{O}$ estamento como base fundante da sociedade e do habitus da universidade brasileira; 2 Uma mudança do habitus nas universidades federais por meio da adoção de políticas públicas de inclusão; $3 \mathrm{O}$ processo inflacionário do diploma universitário e a consequente necessidade do avanço das políticas públicas de inclusão; Considerações Finais; Referências Bibliográficas.

\section{INTRODUÇÃO}

Sabe com quem está falando? De onde vem sua família? Você é filho de quem? Possivelmente, todo brasileiro já ouviu ou proferiu essas indagações, que não demonstram apenas curiosidade, mas também uma forma de buscar referências e de se situar socialmente com o interlocutor, resquícios de uma sociedade ainda calcada no estamento.

O Brasil como nação foi fundado sob a égide do estamento, no qual o privilégio sempre esteve reservado aos donos do poder, para utilizar a expressão cunhada por Raymundo Faoro (2012). Em que pese a impossibilidade de conhecer o presente apenas analisando o passado, sob o risco de realizar uma interpretação vulgar do materialismo histórico (ARON, 1999), é possível concluir que as instituições nacionais também foram influenciadas pela lógica estamental. A universidade pública, portanto, sempre constituiu um privilégio de poucos financiada com recursos de toda coletividade, tornando-se um instrumento para perpetuação das desigualdades sociais.

Desde a fundação da primeira universidade do Brasil - Universidade do Rio de Janeiro, hoje Universidade Federal do Rio de Janeiro - o ensino superior esteve praticamente reservado à elite estamental. Tal fato contribuiu para a formação de um habitus elitista muitas vezes alheio à realidade brasileira. Ressalta-se que o termo habitus refere-se à concepção bourdiesiana, ou seja, "um conhecimento adquirido e também um haver, um capital" (BOURDIEU, 2010, p. 61), podendo, inclusive, ser herdado.

Por muito tempo, a Academia esteve de costas para a sociedade, sobretudo no que se refere ao acesso dos excluídos, já que de certa maneira, a Universidade Pública forneceu os profissionais e a própria tecnologia à sociedade em geral. Com o advento das políticas públicas de inclusão, o ensino superior tornou-se acessível para as camadas historicamente marginalizadas. Assim, houve uma gradual transformação do habitus da universidade brasileira. Contudo, o processo de inclusão gerou efeitos colaterais, como a inflação do diploma universitário, fenômeno diretamente relacionado com o aumento da oferta de vagas aliado à democratização do acesso ao nível superior.

Em que pese uma aparente positividade, esse fenômeno revela que a simples inclusão de jovens provenientes das classes menos favorecidas nas universidades públicas por si só não é capaz de promover uma transformação na estrutura da sociedade. Assim, é necessário pensar além, para depois da formatura, quando o beneficiário da política pública de inclusão tiver que ingressar no mercado de trabalho.

No que tange ao método, é essencial identificar as operações mentais e técnicas de pesquisa para que um conhecimento possa ser considerado científico (GIL, 2006). Portanto, método científico nada mais é que o conjunto de procedimentos adotados para atingir o conhecimento. Há diversos métodos e cada qual é passível de críticas. Nesse sentido, existem três 
grandes linhas metodológicas de destaque na pesquisa social aplicada e jurídica (GUSTIN, 2015), quais sejam, a linha da tecnologia social científica; a linha metodológica de sentido jurisprudencial; e a linha crítico-metodológica. Dessas linhas derivam diferentes vertentes teórico-metodológicas.

Por conseguinte, adotou-se o método estatístico, fundado na aplicação da teoria estatística, que constitui um grande auxílio para a investigação a ser realizada, visto que garantem a objetividade e a precisão no estudo dos dados documentais disponíveis.

Mediante a utilização de testes estatísticos, torna-se possível determinar, em termos numéricos, a probabilidade de acerto de determinada conclusão, bem como a margem de erro de um valor obtido. Portanto, o método estatístico passa a caracterizar-se por razoável grau de precisão, o que torna bastante aceito por parte dos pesquisadores com preocupações de ordem quantitativa.

Os procedimentos estatísticos fornecem considerável reforço às conclusões obtidas, sobretudo mediante a experimentação e observação. Tanto é que os conhecimentos obtidos em alguns setores da Psicologia e da Economia desenvolvem-se fundamentalmente à utilização do método estatístico. (GIL, 2006, p.35)

O presente artigo, portanto, pretende analisar como a origem estamental da sociedade brasileira interferiu no habitus excludente da universidade, para em um segundo momento traçar como as políticas públicas de inclusão adotadas na última década proporcionaram sua alteração. Por fim, o fenômeno da inflação do diploma será abordado, com o intuito de estabelecer diretrizes para a efetivação da inclusão social da parcela que sempre esteve marginalizada. Afinal, não é possível corrigir as desigualdades de uma sociedade historicamente fundada sobre privilégios com poucas políticas inclusivas e em poucos anos.

\section{O ESTAMENTO COMO BASE FUNDANTE DA SOCIEDADE E DO HABITUS DA UNIVERSIDADE BRASILEIRA}

A imensa desigualdade social é a raiz de muitos dos problemas enfrentados pelo Brasil. Para entender esse fenômeno e analisar como a universidade brasileira historicamente serviu como meio de concentração de renda, é necessário compreender como o estamento social influenciou na formação da sociedade brasileira.

A partir dessa constatação será possível entender como o habitus legitima a possessão da elite no ambiente universitário, uma vez que o estamento influenciou a formação das universidades brasileiras, sendo a educação um capital simbólico, ou seja, fator de distinção social. Por outro lado, a própria academia historicamente justificou a dominação da elite no campo universitário (SOUZA, 2015), fator de legitimação da imensa desigualdade social do país.

Após três décadas da chegada de Pedro Álvares Cabral, temendo o assédio dos traficantes franceses de pau-brasil, o rei D. João III e seus conselheiros percebem que só há uma alternativa para a manutenção do imenso território reivindicado: Colonizar. Portanto, a colonização foi um empreendimento de Estado, sendo as capitanias delegações públicas de poderes aos particulares (FAORO, 2012).

Foi transplantado para a colônia ultramarina a mesma organização social portuguesa denominada estamento, fundada no patrimonialismo e na concessão de privilégios, bem como projetada de cima para baixo, ou seja, estratificada a partir de critérios socioculturais como honra, tradição e prestígio (WEBER, 1982). Nesse sentido, cabe a crítica realizada por Jessé Souza aos sociólogos clássicos brasileiros, que entendem "o conceito de patrimonialismo perde qualquer contextualização histórica, fundamental no seu uso por Max Weber e passar a designar uma espécie de 'mal de origem' da atuação do Estado enquanto tal em qualquer período histórico" (SOUZA, 2015, p. 66). 
A estratificação é o modo de estruturação da sociedade e acaba por influenciar a distribuição do poder, seja econômico, militar ou cultural. Destarte, o estamento configura uma comunidade na qual seus membros pensam e agem conscientes de pertencerem ao mesmo grupo social, que aparenta uma maior qualificação para o exercício do poder.

A situação estamental, a marca do indivíduo que aspira aos privilégios do grupo, se fixa no prestígio da camada, na honra social que ela infunde sobre toda a sociedade. Esta consideração social apura, filtra e sublima um modo ou estilo de vida; reconhece, como próprias, certas maneiras de educação e projeta prestígio sobre a pessoa que a ele pertence; não raro hereditariamente. Para incorporar-se a ele, não há a distinção entre o rico e o pobre, o proprietário e o homem sem bens. Ao contrário da classe, no estamento não vinga a igualdade de pessoas - o estamento é, na realidade, um grupo de membros cuja elevação se calca na desigualdade social (FAORO, 2012, p. 61).

O estamento é instituído nas distinções mantidas por convenções e leis, que asseguram aos grupos dominantes privilégios e monopólios. Por conseguinte, o direito português, precocemente consolidado, foi determinante para articulação do Estado estamental, pois o direito dito pelo monarca absolutista deveria ser escrito. Para tanto, era necessário funcionários para redigir bem como para selar a norma, autenticando sua veracidade. Portanto, esses funcionários deveriam ser letrados. Assim, os primeiros burocratas eram provenientes do clérigo. Posteriormente, com o avanço da burocracia estatal, o corpo de juristas fora formado pelas universidades. Para justificar o poder absoluto do rei, os juristas ascendem ao mais elevado grau na burocracia lusitana, assumindo postos nos conselhos e órgãos executivos (FAORO, 2012).

As universidades europeias, gradativamente, tornaram-se centros formadores da elite burocrata. Ou seja, universidades, que incialmente serviam à formação do Clero, constituíram-se também como o centro formador da burocracia estatal, ou seja, do poder. Logo, o quadro administrativo é configurado por uma minoria oriunda das universidades, mormente da Universidade de Coimbra, o que eleva essas instituições como incubadoras da elite estamental.

Na América Portuguesa, o Estado estamental era personificado por quatro figuras: o juiz, o cobrador de tributos e rendas, o militar e o padre. Desse modo, o quadro administrativo da colônia, talvez com a exceção do militar, era formado pela universidade e já nasce excludente. Por conseguinte, a sociedade brasileira foi estruturada sob o signo do privilégio estamental, no qual o ensino, sobretudo o superior, consistia como um fator de distinção social.

Nem o processo descolonização, que culminou com a Independência (1822), e tampouco a Proclamação da República (1899) romperam com a organização estamental da sociedade brasileira. O Brasil, enquanto nação soberana, ingressou no século XX com a mesma organização social colonial. Durante a Primeira República, o ensino superior, assim como diversos outros bens, permaneceu como monopólio estamental.

Essa monopolização ocorre positivamente quando só o grupo em questão está habilitado a possuí-los e a controlá-los; e negativamente quando, a fim de manter seu modo de vida específico, o estamento não deve possuí-los e controlá-los (WEBER, 1982, p. 223).

A universidade brasileira historicamente serviu como estrutura de legitimação da elite dominante, haja vista que o tempo de estudo é fator de justificação da elevada disparidade de renda. Ademais, a elite apropria-se das vagas nas instituições públicas de ensino superior, enquanto os demais, que não possuem condições de competir pela mesma vaga, acabam pagando pelo ensino particular. Mesmo após a Revolução de 1930, quando os latifundiários cafeicultores são obrigados a dividir o poder com a emergente burguesia urbana e a sociedade passa a se estratificar de acordo 
com suas relações de produção, o quadro estamental das universidades não se altera, em que pese o surgimento de uma nova perspectiva do ensino superior, qual seja, o interesse econômico vinculado ao mercado, como se depreende da análise de Gadotti ao indicar que,

A burguesia, libertada pela alienação da força de trabalho, não acumula apenas o capital material, mas igualmente o "capital cultural". A educação e a ciência tornam-se propriedade exclusiva, monopólio do capital. Como diz Roger Dangevillle, “toda a questão da 'educação' se reduz ao final de contas à relação de trabalho necessário e tempo de trabalho livre (para se expandir e não para fazer nada, como sugere irresistivelmente a presente sociedade de sobretrabalho), ou seja, à apropriação do tempo livre pela burguesia ou o proletariado. Não se poderá resolver o antagonismo entre tempo de trabalho e tempo livre senão generalizando para todos o trabalho manual, o que dará a cada um tempo livre para expandir" (GADOTTI, 2006, p. 54).

Consequentemente, as universidades brasileiras, em especial as instituições públicas, devido ao seu elitismo, tornaram-se um mundo à parte da realidade social brasileira, o que refletiu muitas vezes na produção acadêmica, particularmente nas ciências sociais, posto que "as estruturas cognitivas utilizadas pelos agentes sociais para conhecer praticamente o mundo social são estruturas sociais incorporadas" (BOURDIEU, 2017, p. 435). De fato, quando todos os agentes de determinado campo social compartilham a mesma origem social, há um inevitável afastamento com a realidade social, que no Brasil é bastante complexa e desigual.

Ressalta-se que o campo social é o fator determinante para o comportamento dos agentes sociais, fazendo com que suas atitudes, seus modos de agir, socialmente explicáveis, socialmente construídas, não passem pela consciência de quem age. É o que Pierre Bourdieu denomina de habitus, ou seja, quando não há necessidade de raciocinar para se orientar de maneira racional num determinado campo. Portanto, a universidade constitui um campo social no qual seus agentes compartilham o mesmo habitus, pois

Os condicionamentos associados a uma classe particular de condições de existência produzem habitus, sistemas de disposições duráveis e transponíveis, estruturas estruturadas predispostas a funcionar como estruturas estruturantes, ou seja, como princípios geradores e organizadores de práticas e de representações que podem ser objetivamente adaptadas ao seu objetivo sem supor a interação consciente de fins e o domínio expresso das operações necessárias para alcançálos, objetivamente "reguladas" e "regulares" sem em nada ser o produto da obediência a algumas regras e, sendo tudo isso, coletivamente orquestradas sem ser o produto da ação organizadora de um maestro (BOURDIEU, 2009, p. 87).

Existe uma correlação entre o conceito da habitus e campo social, visto que "a teoria praxiológica, ao fugir dos determinismos das práticas, pressupõe uma relação dialética entre sujeito e sociedade, uma relação de mão dupla entre habitus individual e a estrutura de um campo, socialmente determinado" (SETTON, 2002, p. 64). Por conseguinte, as ações individuais (comportamentos, desejos, aspirações etc.), ao mesmo tempo em que interferem no campo social, são afetadas por este mesmo campo, o que cria um sistema integrado de interferências entre indivíduos e campos, razão pela qual muitas vezes certos comportamentos são involuntários. Por ser inconsciente, tende a parecer natural, mas nada mais é que uma construção social. A influência da sociedade no comportamento do indivíduo, portanto, é mais significativa naquilo que não se percebe.

O habitus é o resultado das diversas interações sociais que determinada pessoa mantém durante a vida, ou seja, constitui-se como um conjunto de relações que se engendram em espaços variados, como a família, escola, trabalho. Assim, a mudança do habitus de um determinado campo 
social é um processo lento. Entretanto,

É possível identificar a ordem social contemporânea, fazendo emergir novas formas de interação social, contribuindo para a produção de um habitus alinhado às pressões modernas. Ou seja, vivendo a realidade da desinstitucionalização das agências socializadoras, propenso a interagir com uma nova conjuntura social, o indivíduo contemporâneo é expressão e produto de um novo habitus social (SETTON, 2002, p. 67).

Nesse sentido, os avanços nos meios de comunicação potencializaram a capacidade de transmutação do habitus, visto que as pessoas estão altamente conectadas umas com as outras, sendo influenciadas por campos sociais virtuais, formados por indivíduos e instituições de várias partes do mundo. As redes sociais nada mais são que campos virtuais, possuindo a mesma capacidade de interferência no habitus que qualquer outro campo social.

Por sua vez, a universidade brasileira, fundada sob a égide da elite estamental, não ficou alheia à mudança do habitus na contemporaneidade. A adoção de políticas públicas inclusivas para parcelas sociais historicamente afastadas do ensino superior, ao mesmo tempo que tornou esse espaço mais democrático, causou um choque decorrente do ingresso de agentes estranhos ao campo. Esse agente estranho, contudo, logo passa a agir de maneira alinhada com as expectativas sociais do campo de forma natural, o que Bourdieu chama "senso prático", constituindo

[...] Um dos efeitos fundamentais do acordo entre o senso prático e o senso objetivado é a produção em um mundo de senso comum, cuja evidência imediata se reveste da objetividade que o consenso sobre o sentido das práticas e do mundo assegura, isto é, a harmonização das experiências e o reforço contínuo que cada uma delas recebe da expressão individual ou coletiva (em uma festa, por exemplo), improvisada ou programada (lugares comuns, ditados), de experiências semelhantes ou idênticas (BOURDIEU, 2009, p. 95-96).

Portanto, a democratização da universidade oportuniza uma ascensão social aos indivíduos historicamente marginalizados, bem como aumenta a capilaridade da universidade em toda sociedade. As distinções estamentais, legitimadas pela ideia deformada de meritocracia, perdem importância em prol da justiça social e da democratização do ensino superior. A mudança do habitus, apesar de ser um processo lento e gradual, já é perceptível nos diversos campi espalhados pelo Brasil.

\section{UMA MUDANÇA DO HABITUS NAS UNIVERSIDADES FEDERAIS POR MEIO DA ADOÇÃO DE POLÍTICAS PÚBLICAS DE INCLUSÃO}

As Instituições Federais de Ensino Superior (IFES), de modo geral, constituem o que Pierre Bourdieu denomina campo social, por serem espaços de posições sociais ocupadas pelos agentes sociais. Portanto, entender

A teoria geral da economia dos campos permite descrever e definir a forma específica de que se revestem, em cada campo, os mecanismos e os conceitos mais gerais (capital, investimento, ganho), evitando assim todas as espécies de reducionismo, a começar pelo economismo, que nada mais conhece além do interesse material e a busca da maximização do lucro monetário. Compreender a gênese social de um campo, e aprender aquilo que faz a necessidade específica da crença que o sustenta, do jogo de linguagem que nele se joga, das coisas materiais e simbólicas em jogo que nele se geram, é explicar, tornar necessário, subtrair ao absurdo do arbítrio e do não-motivado os atos dos produtores e as obras por eles 
produzidas e não, como geralmente se julga, reduzir ou destruir (BOURDIEU, 2010, p. 69).

Desse modo, o campo social determina o comportamento dos agentes sociais, fazendo com que suas atitudes, seus modos de agir, socialmente explicáveis, socialmente construídos, não passem pela consciência de quem age. É o que o sociólogo francês denomina habitus, ou seja, quando não há necessidade de raciocinar para se orientar de maneira racional num determinado campo.

Nesse âmbito, o Decreto $n^{\circ}$ 7.234, de 19 de julho de 2010, dispõe sobre o Programa Nacional de Assistência Estudantil (PNAES), que prioriza a assistência estudantil aos discentes oriundos da rede pública de educação básica, bem como com renda familiar per capita de até um salário mínimo e meio. Portanto, é importante o percentual de estudantes nesta faixa de renda para definição das políticas públicas por parte das IFES. A Tabela 1 mostra a faixa de renda per capita dos discentes.

TABELA 1: Graduandos por faixa de renda per capita do grupo familiar

\begin{tabular}{|l|c|}
\hline Faixa de renda mensal per capita & $\%$ \\
\hline Até meio salário mínimo & 26,6 \\
\hline De meio até um salário mínimo & 26,9 \\
\hline Mais de um até um e meio salário mínimo & 16,6 \\
\hline Subtotal até um e meio salário mínimo & $\mathbf{7 0 , 2}$ \\
\hline Mais de um e meio até três salários mínimo & 16,7 \\
\hline Mais de três até cinco salários mínimos & 5,9 \\
\hline Mais de cinco até sete salários mínimos & 2,8 \\
\hline Mais de sete até dez salários mínimos & 0,8 \\
\hline Mais de dez até vinte salários mínimos & 0,6 \\
\hline Mais de vinte salários mínimos & 0,1 \\
\hline Não respondeu & 3,0 \\
\hline Total & $\mathbf{1 0 0}$ \\
\hline
\end{tabular}

FONTE: V Pesquisa Nacional de Perfil Socioeconômico e Cultural dos (as) graduandos (as) das IFES (2018).

Com a publicação da Lei $n^{\circ}$ 12.711, de 29 de agosto de 2012, as Instituições Federais de Ensino Superior passaram a reservar $50 \%$ (cinquenta por cento) de suas vagas em cursos de graduação aos candidatos provenientes de escolas públicas. Dentro deste universo, metade das vagas foram reservadas aos estudantes com renda familiar inferior a 1,5 (um e meio) salário mínimo per capita.

A adoção da política de cotas, de certa forma, alterou a realidade social das instituições federais de ensino superior. Tal realidade, como já demonstrado, não é aleatória, constituindo-se como produto da ação humana, sujeita às transformações pelos próprios homens, sobretudo dos socialmente oprimidos (FREIRE, 1975), uma vez que os filhos da classe dominada, devido ao deficiente ensino básico público, não conseguem transpor o processo seletivo das universidades públicas.

Há uma evidente proporcionalidade entre a qualidade de ensino e o nível de exigência para aprovação no processo seletivo. Assim, a lógica meritocrática funciona como uma cortina de fumaça, pois esconde a grande desigualdade entre os candidatos oriundos do ensino básico público e privado, ao mesmo tempo que estabelece uma aparente justiça na seleção pelas melhores notas. O apego à meritocracia deslegitima as políticas públicas de inclusão (MELO et al, 2015), já que a vinculação do mérito somente à nota do processo seletivo esconde toda estrutura desigual da sociedade brasileira.

De outro modo, por historicamente estar vinculado à elite estamental, o diploma universitário, sobretudo dos cursos mais concorridos, possui um poder simbólico, capaz de promover a diferenciação social. Assim, a política pública de cotas constitui meio efetivo de promoção de justiça social, pois oportuniza ascensão social aos indivíduos marginalizados, o que

Revista de Direito Brasileira | Florianópolis, SC | v. 27 | n. 10 | p.398-411 | Set./Dez. 2020 
aumenta seu capital social, que é definido como

[...] o conjunto de recursos atuais ou potenciais que estão ligados à posse de uma rede durável de relações mais ou menos institucionalizadas de interconhecimento e de inter-reconhecimento ou, em outros termos, à vinculação de um grupo, como conjunto de agentes que não somente são dotados de propriedades comuns (passíveis de serem percebidas pelo observador, pelos outros ou por eles mesmos), mas também são unidos por ligações permanentes e úteis. Essas ligações são irredutíveis às relações objetivas de proximidade do espaço físico (geográfico) ou no espaço econômico e social porque são fundadas em trocas inseparavelmente materiais e simbólicas cuja instauração e perpetuação supõe o re-conhecimento dessa proximidade. $\mathrm{O}$ volume do capital social que um agente social possui depende então da extensão da rede de relações que ele pode efetivamente mobilizar e do volume do capital (econômico, cultural ou simbólico) que é posse exclusiva de cada um daqueles a quem está ligado. Isso significa que, embora seja relativamente irredutível ao capital econômico e cultural possuído por um agente determinado ou mesmo pelo conjunto de agentes a quem está ligado (como bem se vê no caso do novo rico), o capital social não é jamais completamente independente deles pelo fato de que as trocas que instituem o interreconhecimento supõe o reconhecimento de um mínimo de homogeneidade "objetiva" e de que ele exerce um efeito multiplicador sobre o capital possuído com exclusividade (BOURDIEU, 2007, p. 67).

Esse capital social, por sua vez, é herdado da família no processo de formação do indivíduo, validando a identidade social e a transmissão de valores, virtudes e competências. Por consequência, um elevado capital social herdado aumenta as chances de sucesso escolar, enquanto a fragilidade ou ausência desse capital pode ser determinante para o insucesso.

Daí a importância das políticas públicas de inclusão para correção das desigualdades estruturais da sociedade brasileira. Prestes a completar o prazo de dez anos previsto pela Lei $\mathrm{n}^{\circ}$ 12.711/2012 de revisão do programa especial para o acesso às instituições de educação superior de estudantes pretos, pardos e indígenas e de pessoas com deficiência, bem como daqueles que tenham cursado integralmente o ensino médio em escolas públicas, é possível perceber a constituição de um novo habitus nas instituições federais de ensino superior.

Os dados da V Pesquisa Nacional do Perfil Socioeconômico e Cultural dos Estudantes de Graduação das Instituições Federais de Ensino Superior (IFES), elaborado pela Associação Nacional dos Dirigentes das Instituições Federais de Ensino (ANDIFES), em parceria com o Fórum Nacional dos Pró-Reitores de Assuntos Estudantil (FONOPRACE) e com o Centro de Pesquisas Econômico-Sociais da Universidade Federal de Uberlândia (Cepes/UFU), apontam que o perfil racial dos estudantes da IFES brasileiras mudou significativamente nos últimos anos, aproximando-se mais do perfil da população. Pela primeira vez, o percentual de estudantes autodeclarados negros e pardos constitui a maioria absoluta, alcançando 51,2\% do universo. Em que pese o perfil de cor e raça da população brasileira tenha também se alterado, o aumento de pretos, pardos e indígenas identificado na Pesquisa foi superior ao crescimento populacional. $\mathrm{O}$ Gráfico 1 revela o perfil dos graduandos das IFES segundo a autodeclaração. 
GRÁFICO 1: Cor e raça do corpo discente das IFES

$\begin{array}{lll}\text { - Brancos (43,3\%) } & \text { - Pardos (39,2\%) } & \text { - Negros (12,0\%) } \\ \text { - Amarelos (2,0\%) } & \text { - Indígenas (0,9\%) } & \text { - Sem Declaração }(2,6 \%)\end{array}$

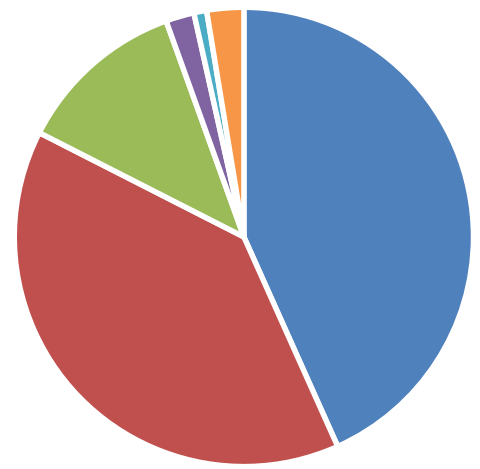

FONTE: V Pesquisa Nacional de Perfil Socioeconômico e Cultural dos (as) graduandos (as) das IFES (2018).

A mesma pesquisa revela, ainda, que a média de renda per capita dos discentes é de $\mathrm{R} \$$ 1.328,08 (mil trezentos e vinte e oito reais e oito centavos), ou seja, muito semelhante à renda média per capita do brasileiro, que segundo o Instituto Brasileiro de Geografia e Estatística (IBGE) é no valor de $\mathrm{R} \$ 1.373,00$ (mil trezentos e setenta e três reais). Portanto, percebe-se que as universidades federais estão mais inclusivas. Contudo, é importante ressaltar que devido a imensa desigualdade social do Brasil, o corpo discente das IFES não faz parte da camada mais pobre da população, uma vez que os setores mais pobres e miseráveis nem mesmo chegam a concluir o ensino básico, principal fator de exclusão do ensino superior. O Gráfico 2 mostra o processo de inclusão dos graduandos de renda mais baixa no nas IFES, sobretudo após a vigência da Lei $n^{\circ}$ $12.711 / 2012$.

GRÁFICO 2: Percentual de (as) graduandos (as) das IFES, segundo faixas de renda mensal familiar per capita selecionadas, por ano de realização da Pesquisa de Perfil - 1996 - 2018 (em \%)

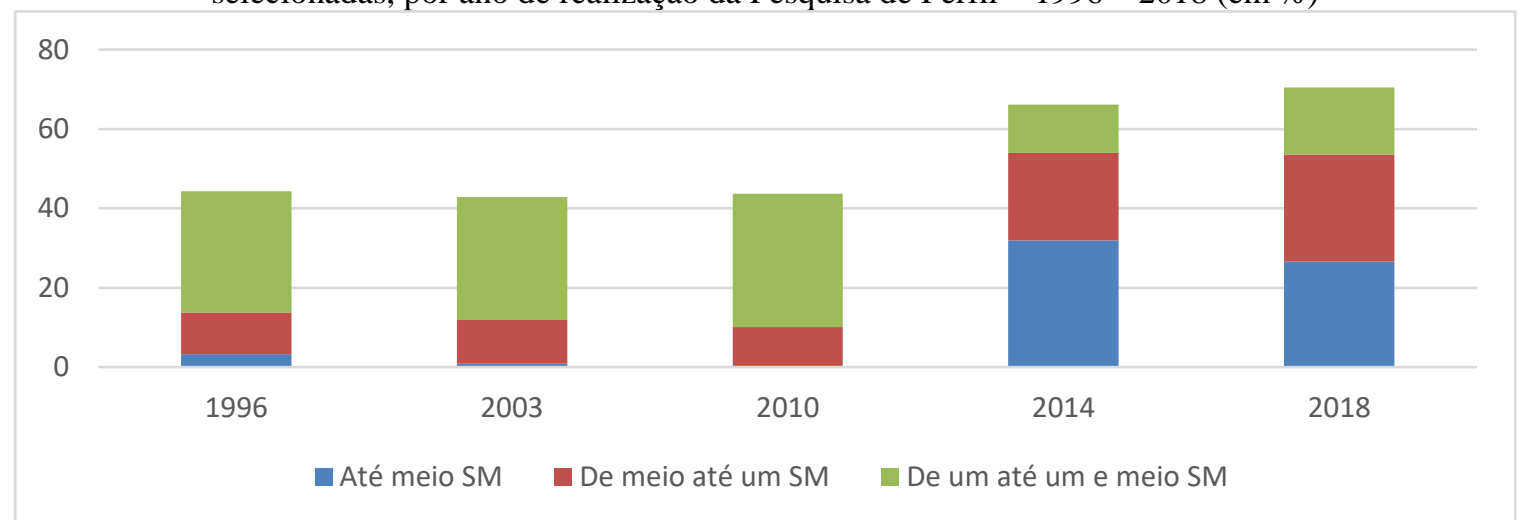

FONTE: V Pesquisa Nacional de Perfil Socioeconômico e Cultural dos (as) graduandos (as) das IFES (2018).

Os dados da V Pesquisa Nacional de Perfil Socioeconômico e Cultural dos (as) graduandos (as) das IFES apontam uma mudança do habitus nas universidades federais. Há uma crescente incorporação de graduandos das classes sociais mais baixas nos últimos anos, oriundos de escolas públicas, negros e pardos. A democratização das IFES é resultado de políticas públicas inclusivas, que a longo prazo reduzirão as desigualdades sociais no país, sobretudo entre brancos e negros.

A Tabela 2, por sua vez, compara a população brasileira, segundo critérios de raça e cor, com os discentes das IFES e traça a mudança desse perfil nos últimos anos. 
TABELA 2: Graduandos e população brasileira segundo cor e raça (\%)

\begin{tabular}{|c|c|c|c|c|c|c|}
\hline \multirow{3}{*}{ Brancos } & & $\mathbf{2 0 0 3}$ & $\mathbf{2 0 1 0}$ & $\mathbf{2 0 1 4}$ & $\mathbf{2 0 1 8}$ & Variação \\
\cline { 2 - 7 } & IFES & 59,4 & 53,9 & 45,6 & 43,3 & $-11,6$ \\
\hline \multirow{2}{*}{ Negros } & Brasil & 51,9 & 47,7 & 45,4 & 38,6 & $-13,3$ \\
& IFES & 5,9 & 8,7 & 9,8 & 12,0 & $+6,1$ \\
\cline { 2 - 7 } & Brasil & 5,9 & 7,6 & 8,5 & 8,1 & $+2,2$ \\
\hline \multirow{2}{*}{ Pardos } & IFES & 28,3 & 32,0 & 37,7 & 39,2 & $+10,9$ \\
\cline { 2 - 7 } & Brasil & 41,1 & 43,1 & 45,0 & 52,5 & $+11,4$ \\
\hline \multirow{2}{*}{ Asiáticos } & IFES & 4,5 & 3,0 & 2,3 & 2,0 & $-2,5$ \\
\cline { 2 - 7 } & Brasil & 0,4 & 1,0 & 0,5 & 0,5 & $+0,1$ \\
\hline \multirow{2}{*}{ Indígenas } & IFES & 2,0 & 0,9 & 0,6 & 0,9 & $-1,1$ \\
& Brasil & 0,2 & 0,4 & 0,4 & 0,4 & $+0,2$ \\
\hline
\end{tabular}

FONTE: V Pesquisa Nacional de Perfil Socioeconômico e Cultural dos (as) graduandos (as) das IFES (2018).

Realizando uma análise fria dos dados, percebe-se que a população negra é proporcionalmente maior nas IFES do que na população brasileira. Contudo, tal conclusão merece maior análise, pois é sabido que ainda há um grande estigma em ser negro no Brasil, o que faz com que muitos negros se declarem como pardos. Por outro lado, a aceitação da negritude aumenta com o maior nível de estudo. Ademais, o percentual de estudantes cotistas é crescente; em 2018 48,3\% dos graduandos das IFES ingressaram pelo sistema de cotas (FONAPRACE, 2018).

Portanto, não é possível concluir que há um favorecimento de qualquer classe social dentro das IFES, pois a população acadêmica é muito similar à população do país. Contudo, apesar dos avanços, o ensino superior ainda é utópico para a classe mais desfavorecida da sociedade, pois muitos não conseguem concluir o ensino básico.

Os referidos dados mostram que, apesar de todo o avanço da última década, a democratização do ensino superior ainda não está completa. As camadas mais representativas da população brasileira ainda não conseguem ter acesso ao ensino superior de qualidade, à pesquisa, à cultura e ao conhecimento (FRANCO; CUNHA, 2017), o que é de vital importância para o combate das desigualdades sociais e ao aprimoramento do capital humano.

De todo modo, é possível concluir que houve uma significativa alteração do habitus nas universidades federais devido à política de cotas. Isso mostra que, apesar de durável, o habitus não é eterno, podendo ser transformado por meio de políticas públicas inclusivas. $\mathrm{O}$ diploma universitário é um sonho possível e realizável para grande parte da população brasileira, enquanto a universidade não é mais reduto da elite estamental.

\section{O PROCESSO INFLACIONÁRIO DO DIPLOMA UNIVERSITÁRIO E A CONSEQUENTE NECESSIDADE DO AVANÇO DAS POLÍTICAS PÚBLICAS DE INCLUSÃO}

A democratização do acesso às universidades federais e a expansão do número de vagas no ensino superior, conquistada a duras penas, provocaram um efeito colateral, já percebido nos países desenvolvidos, qual seja, a inflação do diploma universitário. Esse fenômeno mostra-se aqui mais complexo devido as particularidades da sociedade brasileira, além de expor como o capital cultural é facilmente precificado na lógica capitalista.

O processo de inclusão das camadas historicamente excluídas no ensino superior não resultou necessariamente numa ascensão social, visto que o crescimento do número de graduados tem por consequência o aumento da massa do capital cultural, o que produz um efeito inflacionário por tornar o diploma acessível a maior número de pessoas.

Dito de outra forma, o sistema injusto de perpetuação dos interesses dos detentores do poder, consegue até mesmo impedir que, a ascendência formal não implica necessariamente na ascensão social, já que essa é a lógica do capitalismo, como nos indica Bourdieu, 
A transformação da distribuição dos cargos entre os portadores de títulos que resulta automaticamente do crescimento do número de titulados faz com que, a cada momento, uma parte dos portadores de títulos - e sem dúvida, em primeiro lugar, os que são mais desprovidos dos meios herdados para fazer valer os diplomas - seja vítima da desvalorização. As estratégias com as quais aqueles que estão mais expostos à desvalorização esforçam-se por lutar [...] contra essa desvalorização constituem um dos fatores determinantes do crescimento do número de diplomas distribuídos que, por sua vez, contribui para a desvalorização. A dialética da desvalorização e recuperação tende, assim, a nutrir-se a si própria (BOURDIEU, 2007, p. 152).

Ademais, o aumento do número de vagas no mercado de trabalho não foi proporcional ao crescimento da massa de diplomados, causando frustração nos jovens que possuíam a expectativa de ascensão social após a formatura. No Brasil, particularmente, a estagnação econômica acentuou esse processo de desvalorização, fazendo com que muitos formados continuassem excluídos do mercado formal de trabalho ou prestando serviços de forma precarizada. Tal fenômeno, contudo, não é apenas nacional. Como aponta Ulrich Beck,

[...] os universitários já não estão em condições de planejar suas carreiras a longo prazo. Para eles, a crise do mercado de trabalho e da sociedade do trabalho se revela menos como perda profissional do que como perda da segurança em contar com uma profissão bem remunerada e prestigiosa. O futuro profissional após a formação universitária não se perde no caminho, mas se torna imprevisível e incalculável. Consequentemente, o planejamento de longo prazo é, com frequência, substituído pela dedicação às possibilidades passageiras. Isso pode significar que, na saturação com conteúdos profissionalizantes cada vez menos realistas, a fome por educação é redescoberta (BECK, 2011, p. 227).

Destarte, por falta de perspectivas, muitos optam por ingressar em programas de pósgraduação stricto sensu sem necessariamente possuírem vocação acadêmica, o que resulta no grande número de desistências e consequente desligamento. Infelizmente, mesmo quando conseguem defender dissertação ou tese não existe garantia de locação profissional, tendo em vista o elevado número de mestres e doutores desempregados. Assim, muitos não possuem outra alternativa senão emigrarem para outros países, processo esse conhecido como fuga de cérebros, o que faz com que o investimento público no capital humano da ciência seja dado de presente para outras nações.

Fora do campo acadêmico, o diploma vale o que, econômico e socialmente, vale o seu portador (BOURDIEU, 2007). Por conseguinte, o sucesso profissional após a conquista do diploma depende mais do capital econômico e social do que propriamente do capital acadêmico. Noutras palavras, o indivíduo de uma classe privilegiada possui maiores chances de sucesso profissional que seu colega de classe mais baixa, seja pelas relações sociais ou por simplesmente ter o luxo de após formado continuar a estudar para algum concurso público.

Por outro lado, aquele que não possui o capital econômico e social, não tem outro recurso para defender o valor do seu diploma a não ser a recusa em vender sua força de trabalho pelo preço que lhe é ofertado. Isso explica o fenômeno cada vez mais comum de indivíduos que após a graduação não trabalham e tampouco continuam estudando, denominado de "geração nem-nem". Logo, essa geração foi de certa forma enganada ao acreditar que o diploma universitário garantiria meios de ascensão social, só restando a desilusão coletiva.

A tendência é de que os beneficiários dos programas de inclusão tenham maiores dificuldades para o ingresso no mercado de trabalho após a formatura. Por consequência, acabam permanecendo no mesmo emprego que possuíam antes do diploma, o que faz com que tenham a percepção que os anos passados na universidade tenham sido inúteis. "Um diploma já não é 
suficiente para obter uma determinada posição profissional e, com ela, os respectivos prestígio e renda" (BECK, 2011, p. 224).

Entretanto, isso não significa que a educação superior se tornou prescindível. Ao contrário, há uma inflação do diploma pelo fato do mesmo não mais representar um fator de distinção da mão-de-obra, haja vista que a expansão universitária não foi absorvida pela economia, fazendo com que o desemprego seja latente até para áreas há poucos anos consideradas garantias de empregabilidade, como medicina, direito, engenharia. Para além do diploma, o indivíduo necessita ser fluente em dois ou três idiomas estrangeiros, ter noções de computação, realizar cursos complementares. Ou seja, a exigência educacional é cada vez maior.

A depreciação do diploma universitário tornou-o o mínimo exigível para qualquer vaga no mercado de trabalho. O egresso da universidade vê-se obrigado a aceitar empregos não qualificados e fora da sua área de formação para evitar a tragédia do desemprego, o que, mais uma vez, gera frustração.

Devido a abundância inflacionária na oferta de mão-de-obra qualificada, a decisão de contratação para preenchimento de determinada vaga de trabalho passa a não depender tanto das qualificações dos candidatos. Assim, antigos critérios seletivos (raça, gênero, idade, estado de saúde, convicções políticas, vínculos sociais) voltam a interferir na contração de um empregado. Noutras palavras, depois de todo avanço para democratização do ensino superior e a consequente mudança no seu habitus, há claro indícios do renascimento dos critérios estamentais para oferta de oportunidades.

Desse modo, a política de inclusão no ensino superior não significou necessariamente em igualdade de oportunidades para todos. Houve apenas uma prorrogação no processo de exclusão social, que antes ocorria no processo seletivo para o ingresso na universidade e hoje dá-se na entrada no mercado de trabalho. A primeira oportunidade de trabalho é hoje o principal meio de distinção social.

Destaca-se que a Lei nº 9.799/1999, que incluiu o artigo 373-A na Consolidação das Leis do Trabalho (CLT), proíbe recusar emprego, promoção ou motivar a dispensa do trabalho em razão de sexo, idade, cor, situação familiar ou estado de gravidez. Entretanto, ainda é comum a ocorrência dessas situações, provando que a vedação legal por si só é ineficiente para banir critérios estamentais na contratação. É ingenuidade acreditar que a força da lei é capaz de erradicar crenças e valores historicamente enraizados na sociedade (FRIEDMAN, 2019).

Assim, o Estado não deve simplesmente proibir a discriminação por critérios estamentais, vez que isso é inútil. É necessário dar um passo a mais, ou seja, criar políticas públicas para a inclusão das pessoas historicamente discriminadas no mercado de trabalho, já que hoje o diploma universitário não constitui mais meio distintivo. No setor público já existe algumas políticas, como a destinação de vinte por cento das vagas oferecidas nos concursos públicos, no âmbito federal, para negros (Lei $\left.\mathrm{n}^{\circ} 12.990 / 2014\right)$. Contudo, no setor privado ainda falta medidas para estimular o empregador a oferecer oportunidades aos graduados de origem socialmente marginalizada. Evidentemente, não cabe ao poder público obrigar o particular a contratar uma porcentagem de seus funcionários por determinada cor ou classe social, uma vez que isso fere a liberdade de contratar. Entretanto, o Estado pode criar estímulos econômicos para incentivar o empregador a admitir pessoas historicamente marginalizadas.

A inflação do diploma universitário é um fenômeno que indica que a inclusão é um processo longo, que não pode depender de medidas isoladas para se concretizar. A sociedade brasileira ainda guardas resquícios estamentais, por isso é necessário maior atuação do Estado para cumprir um dos objetivos fundamentais da República, qual seja, a erradicação da pobreza e da marginalização, bem como a redução das desigualdades sociais e regionais, conforme dispõe o artigo $3^{\circ}$, inciso III, da Constituição Federal. 


\section{CONSIDERAÇÕES FINAIS}

Em 29 de agosto de 2020 a Lei 12.711/2012 completará oito anos de vigência. Neste período, é possível perceber que uma mudança do habitus nas Instituições Federais de Ensino Superior, que passaram a receber estudantes que até então viam a universidade como um sonho distante. Por outro lado, surge um novo fenômeno resultante da democratização do ensino superior: A inflação do diploma universitário.

Esse fenômeno já era de se esperar. Entretanto, expõe mais uma vez as desigualdades sociais do país, visto que um graduado de renda alta tem mais chances de ingressar no mercado de trabalho que um graduado de renda baixa, mesmo que ambos tenham formado na mesma universidade. As oportunidades no Brasil ainda seguem os critérios estamentais.

Assim, é necessário dar um passo a frente, ou seja, estabelecer políticas públicas de inclusão no mercado de trabalho para os jovens recém formados que foram beneficiados pelo programa de cotas. Não é possível corrigir séculos de desigualdades em apenas dez anos. A construção de um país mais equânime, com fins de atingir um dos objetivos fundamentais da República, passa necessariamente pela adoção de políticas públicas inclusivas, haja vista que a eficácia dessas políticas já foi comprovada.

Ressalta-se, todavia, que não cabe ao Estado usar do seu poder para obrigar os particulares a contratarem os indivíduos oriundo das classes historicamente excluídas. A imposição legal não é uma medida eficaz, pois a burla é sempre possível. Logo, mais que impor, é necessário incentivar, uma vez que o incentivo tem um apelo econômico, condizente com a lógica do sistema capitalista.

Outrossim, a maior política de inclusão é a de pleno emprego. Portanto, o Estado deve ter uma atenção especial à política econômica, já que é inútil ter uma massa de diplomados desempregados ou exercendo funções de baixa qualificação profissional. Não existe antagonismo entre política econômica e política social, ambas são faces da mesma moeda e apresentam uma interdependência. Nesse sentido, só haverá inclusão de fato quando o Brasil ingressar no capitalismo mais elevado, no qual as relações sociais não têm tanta importância, visto que o lucro é o que importa. Enquanto a lógica estamental prevalecer, os donos do poder serão sempre os mesmos.

\section{REFERÊNCIAS}

ARON, Raymond. As Etapas do Pensamento Sociológico. $5^{\text {a }}$ ed. São Paulo: Martins Fontes, 1999.

BECK, Ulrich. Sociedade de risco: Rumo a uma outra modernidade. $2^{\text {a }}$ ed. São Paulo: Editora 34, 2011.

BOURDIEU, Pierre. O Poder Simbólico. 13ª ed. Rio de Janeiro: Bertrand Brasil, 2010.

. A Economia das Trocas Simbólicas. Sérgio Miceli (organizador). $7^{\mathrm{a}}$ ed. São Paulo: Editora Perspectiva, 2011.

. O Senso Prático. Petrópolis: Editora Vozes, 2009.

. A Distinção: crítica social do julgamento. $2^{\mathrm{a}}$ ed. Porto Alegre: Editora Zouk, 2017.

. Escritos de Educação. Maria Alice Nogueira e Afrânio Catani (organizadores). 9a ed. Petrópolis: Editora Vozes, 2007. 
FAORO, Raimundo. Os Donos do Poder: Formação do patronato político brasileiro. $5^{\mathrm{a}}$ ed. São Paulo: Globo, 2012.

FONAPRACE - FÓRUM NACIONAL DE PRÓ-REITORES DE ASSUNTOS

COMUNITÁRIOS E ESTUDANTIS. V Pesquisa Nacional de Perfil Socioeconômico e Cultural dos (as) Graduandos (as) das IFES - 2018. Uberlândia, 2019.

FRANCO, Ana Maria de Paiva; CUNHA, Sara. Perfil Socioeconômico das IFES. In: Radar: tecnologia, produção e comércio exterior. n. 49, fev. 2017.

FREIRE, Paulo. Pedagogia do Oprimido. 2a ed. Rio de Janeiro: Paz e Terra. 1975.

FRIEDMAN, Milton. Capitalismo e liberdade; tradução Afonso Celso da Cunha Serra - Rio de Janeiro: LTC, 2019.

GADOTTI, Moacir. Concepção Dialética da Educação: um estudo introdutório. 15a ed. São Paulo: Cortez, 2006.

GIL, Antonio Carlos. Métodos e Técnicas de Pesquisa Social. $5^{\text {a }}$ ed., São Paulo: Editora Atlas, 2006.

GUSTIN, Miracy Barbosa de Sousa; DIAS, Maria Teresa Fonseca. (Re)Pensando a Pesquisa Jurídica: Teoria e Prática, $4^{\mathrm{a}}$ ed. - Belo Horizonte, 2015.

INSTITUTO BRASILEIRO DE GEOGRAFIA E ESTATÍSTICA. Pesquisa Nacional por Amostra de Domicílios (PNAD), 2018. Disponível em: < https://agenciadenoticias.ibge.gov.br/agencia-sala-de-imprensa/2013-agencia-denoticias/releases/23852-ibge-divulga-o-rendimento-domiciliar-per-capita-2018 >. Acesso em: 13 abr. 2020.

MELO, Patrícia Bandeira de; CAMPOS, Luís Henrique Romani; ZARIAS, Alexandre. O Novo Habitus de Estudantes da Universidade Pública no Interior do Nordeste. In: Cadernos do GEA. Rio de Janeiro, n. 7, p. 26-31, jan-jun. 2015.

SOUZA, Jessé. A Tolice da Inteligência Brasileira: ou como o país se deixa manipular pela elite. São Paulo: LeYa, 2015.

SETTON, Maria da Graça Jacintho. A teoria do habitus em Pierre Bourdieu: uma leitura contemporânea. In: Revista Brasileira de Educação. Rio de Janeiro, n. 20, p. 60-70. mai./jun./jul./ago. 2002.

WEBER, Max. Ensaios de Sociologia. $5^{\text {a }}$ ed. Rio de Janeiro: LTC, 1982. 